\title{
A Risk Performance Measurement System for the Mega-Project
}

\author{
Seon-Gyoo Kim \\ Division of Architecture, Kangwon National University, Chuncheon, Korea
}

\begin{abstract}
In recent years, interests and studies on the urban regeneration projects have been increased and largely conducted. It is a part of the effort that solves some social and economical problems occurred by deteriorated buildings and degraded infrastructures through new urban regeneration projects or redevelopment projects. However, the urban regeneration projects show the characteristics that can not guarantee in the project performance because the projects have various and complex stakeholders related to these projects and are exposed to lots of risks due to its huge scale. This study proposed the risk performance index method to improve the efficiency of the overall performance measurement for a mega-project by extending from the traditional cost/schedule based performance measurement system. The risk performance index method proposed in this study has a similar system to the EVMS, and makes possible to perform a three dimensional integrated performance measurement in cost/schedule/risk through 18 different indexes that compose the risk performance index.
\end{abstract}

Keywords : Risk Management, Performance Index, Performance Measurement, Mega-Project

\section{INTRODUCTION}

\subsection{BACKGROUND}

Recently, there are some significant problems in the urban areas, such as population decline, building deterioration, and low development activities even though there have been increased in population, industries, and development activities. A construction project that has a concept of 'urban regeneration' has been appeared as an alternative plan that solves these problems occurred in urban areas in some various aspects (Kang, 2008). The characteristics of an urban regeneration project represent a very complex figure in project sponsors and stakeholders and a long term period of project life cycle. In particular, most urban regeneration projects are called as a mega-project of threedimensional mixed-use space development.

In general, a mega-project can be defined as a project that requires more than 1 billion dollars ( 1 trillion wons) in project cost, and includes lots of risk factors that cause delays or failures of the project during its life cycle (Flyvbjerg, 2003). Thus, it is important to establish a method and system that manage these risk factors effectively in advance. Moreover, it is necessary to effectively reduce the probability of project failures due to the risk factors by measuring the project performance in a view point of risk management. This study defines a concept of the risk performance index (RPI) that measures a project performance by integrating cost/schedule/risk and adding a view point of risk management to the EVMS, which is a traditional integrated cost/schedule performance measurement system in the construction projects. The purpose of this study improves the overall performance measurement accuracy and efficiency of a mega-project by extending a traditional

This study was performed by the 07 high-tech urban development project (Project No: 07 Urban Regeneration B03) implemented by the KICTEP and sponsored by the Ministry of Land, Transportation and Maritime Affairs. cost/schedule performance measurement system to the risk management through the calculation and analysis method of a risk performance index proposed in this study.

\subsection{SCOPE AND PROCESS}

A scope of this study is limited to a mega-project of three-dimensional mixed-use space development. A process of this study can be summarized as follows:

First, this study investigates the existing performance measurement methods used in the construction projects and surveys advantages and disadvantages in these methods.

Second, this study extracts the needs and expected effects of new performance measurement method of a megaproject in a view point of risk management.

Third, this study proposes a risk performance index and measurement system that is an integrated cost/ schedule/risk performance measurement system similar to the EVMS that is a traditional cost/schedule performance measurement system and familiar with project manages.

Fourth, this study proposes calculation and analysis method of newly proposed risk performance index and its expected effects.

\section{SURVEY OF THE EXISTING PERFORMANCE MEASUREMENT METHODOLOGIES}

A performance management is a system that examines and manages whether the projects implemented by persons or organizations are effectively executed or not, and it consists of four steps such as mission, strategy goal, performance goal, and performance index. A strategy goal means a major policy direction to promote missions including goal, value, and function in an organization. A performance goal is a subordinate concept of the strategy goal, and is the multiple specific goals to achieve throughout major projects or organizations to be performed in a subjective year. 
A performance index is a scale to measure the achievement of the performance goal and level, and is important to quantitatively measure the goal pursuing in the project. If the performance index is developed, the efficiency of the project can be measured by quantitatively comparing and evaluating the achievement and its level of the performance goal.

The existing performance measurement systems used in the construction projects such as EVMS, BSC, KPI and BM\&M were selected as the survey methodologies in this study.

\subsection{EVMS}

The EVMS (Earned Value Management System) is a performance measurement system that has been the most widely used performance measurement system in the construction projects. The EVMS is determined as "a project management technique for measuring project progress in an objective manner, it has the unique ability to combine measurement of scope, schedule, and cost in a single integrated system." by the United States Department of Energy(DOE). Also, Fleming \& Koppleman(1996) defined the EVMS as "a technique used to accurately measure the project's planned value of the defined work against earned value actually accomplished" in his work.

A performance measurement applying by the EVMS is to integrate a project cost and schedule, and compare plan versus actual, and then control them. It can not only calculate their influences from planned budget and actual cost but also forecast schedule reduction or delay and budget overruns at a project completion. The elements of the EVMS can be classified as plan, measurement and analysis elements as shown in Table 1.

\subsection{BSC}

The BSC (Balanced Score Card) is also a representative performance measurement system. The BSC method proposed by Kapan \& Norton(1992) is a strategic management method that overcomes the limits and problems in a performance measurement in a short term period based on the traditional financial or accounting measurement, and provides a way that establishes a performance measurement for overall view point and long term period. It has been largely used to establish the performance index in the construction projects around the world. The BSC consists of financial indicators that represent the results of project execution and customer satisfactions that show operational activities, internal management, and operational indicators for learning and growing.

Although it has advantage that performs its management processes strategically through comprehensively measuring financial and non-financial aspects differed from a traditional measurement method, it has disadvantage such as difficulty to make an agreement on 'what do we measure?' in strategy establishment process because most organizations have differences in strategy and vision for their own goals.

The BCS has a limitation in the evaluation of satisfac- tion level of project success factors even though it is useful on the evaluation of business management because it evaluates the management strategy focused on the operational effectiveness.

Table 1. EVMS Terminologies

\begin{tabular}{|c|c|c|}
\hline \multicolumn{2}{|r|}{ Terminology } & Description \\
\hline \multirow{3}{*}{$\begin{array}{l}\text { Plan } \\
\text { Elements }\end{array}$} & WBS (Work Breakdown Structure) & $\begin{array}{l}\text { A deliverable-oriented } \\
\text { grouping of project ele- } \\
\text { ments }\end{array}$ \\
\hline & CA(Control Account) & $\begin{array}{l}\text { A management control } \\
\text { point at which actual cost } \\
\text { t may be accumulated and } \\
\text { compared to earned value. }\end{array}$ \\
\hline & $\begin{array}{l}\text { PMB (Performance Measurement } \\
\text { Baseline) }\end{array}$ & $\begin{array}{l}\text { The time phased budget } \\
\text { against which contract } \\
\text { performance is measured }\end{array}$ \\
\hline \multirow{3}{*}{$\begin{array}{l}\text { Measurement } \\
\text { Elements }\end{array}$} & $\begin{array}{l}\text { BCWS (Budgeted Cost of Work } \\
\text { Scheduled) }\end{array}$ & $\begin{array}{l}\text { The sum of the budgets for } \\
\text { all planned work scheduled } \\
\text { to be accomplished. }\end{array}$ \\
\hline & $\begin{array}{l}\text { BCWP or EV (Budgeted Cost of } \\
\text { Work Performed) }\end{array}$ & $\begin{array}{l}\text { The sum of the budgets for } \\
\text { completed work and the com- } \\
\text { pleted portions of open } \\
\text { work }\end{array}$ \\
\hline & $\begin{array}{l}\text { ACWP(Actual Cost of Work Per- } \\
\text { formed) }\end{array}$ & $\begin{array}{l}\text { The costs actually incurred } \\
\text { in accomplishing the work } \\
\text { performed }\end{array}$ \\
\hline \multirow{4}{*}{$\begin{array}{l}\text { Analysis } \\
\text { Elements }\end{array}$} & $\begin{array}{l}\text { SV (Schedule Variance) } \\
\text { SPI (Schedule Performance Index) }\end{array}$ & $\begin{array}{l}\mathrm{BCWP}-\mathrm{BCWS} \\
\mathrm{BCWP} / \mathrm{BCWS}\end{array}$ \\
\hline & $\begin{array}{l}\text { CV (Cost Variance) } \\
\text { CPI (Cost Performance Index })\end{array}$ & $\begin{array}{l}\text { BCWP - ACWS } \\
\text { BCWP / ACWS }\end{array}$ \\
\hline & $\begin{array}{l}\text { AV (Accounting Variance) } \\
\text { API(AccountingPerformance Index) }\end{array}$ & $\begin{array}{l}\text { ACWP-BCWS } \\
\text { ACWP / BCWS }\end{array}$ \\
\hline & EAC(Estimate AtCompletion) & $\mathrm{ACWP}+(\mathrm{BAC}-\mathrm{BCWP}) / \mathrm{CPI}$ \\
\hline
\end{tabular}

\section{$2.3 \mathrm{KPI}$}

The key performance indicator (KPI) that is a representative performance measurement system in Britain was established based on the construction renovation movement called "Rethinking Construction" that is aimed to improve productivity in the construction projects promoted in 1998. It can be used to measure not only the performance of a construction, such as construction cost and schedule reduction, but also the performance of a business that includes profits and productivities.

A construction renovation movement is a type of movement for the construction re-recognition and renovation, and can be classified into seven different groups as major performance indexes, such as schedule, cost, quality, customer satisfaction, design change, project performance, health, and safety for the construction process, recognition, production method, and system. A performance can be measured based on this classification, and that is applied to plan the efficiency and the productivity in the construction projects. Finally, it establishes the partnership between government, owner and contractor, and practices the Best Practice. Furthermore, it can be evaluated that it improves the project performance and the cost effectiveness by removing inefficiency and unproductive factors in the construction projects in Britain. 


\subsection{BM\&M}

The BM\&M(Benchmarking \& Metrics) is a performance measurement system established by the Construction Industry Institute (CII) in USA that measures the construction performance for six different sections, such as cost, schedule, safety, design change, rework, and productivity, for each project. A goal of this system is to improve a continuous performance in the construction industries by distributing the Best Practice and extending its application. In addition, it proposes the performance criteria in the construction projects through a continuous measurement and devises the development of partners by providing a self evaluation tool.

\section{NEEDS FOR NEW RISK PERFORMANCE MEAS- UREMENT SYSTEM IN A MEGA-PROJECT}

In recent years, the urban regeneration projects with a large scale have become a mainstream in the development of three-dimensional mixed-use spaces such as residential, commercial, business, public, cultural, and leisure.

Although this type of development shows advantages that satisfies almost requirements in various specific facility groups and also maximizes utilization of the space, it includes lots of risks throughout the project, such as complicated interests within various stakeholders, development concepts to be mixed between private and public sides, operation and maintenance, and property management. In addition, there are few studies on the performance man- agement for reflecting the characteristics of the construction projects because a conventional performance management measures only a visible performance in businesses, such as financial and management performances. In particular, the studies about the risk factors that affect performance management in a mega-project level are very insufficient at the present time.

Therefore, it is necessary to prepare a performance management method related to the risk factors in order to forecast the impact of influencing to overall project performance, and response timely and effectively to the impact through developing a technology that continuously manages the performance related to forecast the risk factors and establish the response strategy in the early stage of a mega-project. Thus, this study defines a concept of the risk performance index for measuring the performance related to the risk factors in the construction projects, and draws its calculation equations and measurement methods. Then, this study proposes a new performance measurement method that considers the intrinsic risk factors that may widely affect to the success or the failure of the project by upgrading a traditional cost/schedule performance measurement.

\section{RISK PERFORMANCE INDEX AND MEASURE- MENT SYSTEM}

\subsection{DEFINITION OF THE RISK PERFORMANCE IN- DEX}

Table 2. Risk Performance Indexes

\begin{tabular}{|c|c|c|c|}
\hline No & Terminology & Definition & Abb. \\
\hline 1 & Cost Risk Performance Index & Performance Index measuring risks related to the project cost & CRPI \\
\hline 2 & Schedule Risk Performance Index & Performance Index measuring risks related to the project schedule & SRPI \\
\hline 3 & Forecasted Cost Risk Value & Cost Risk Value forecasted at the specified project time & FCRV \\
\hline 4 & Forecasted Schedule Risk Value & Schedule Risk Value forecasted at the specified project time & FSRV \\
\hline 5 & Residual Cost Risk Value & Cost Risk Value remaining after subtract eliminated cost risk from FCRV & RCRV \\
\hline 6 & Residual Schedule Risk Value & $\begin{array}{l}\text { Schedule Risk Value remaining after subtract eliminated schedule risk } \\
\text { from FSRV }\end{array}$ & RSRV \\
\hline 7 & Forecasted Cost Impact & Cost Impact forecasted at the specified project time & FCI \\
\hline 8 & Forecasted Schedule Impact & Schedule Impact forecasted at the specified project time & FSI \\
\hline 9 & Actual Cost Impact & Cost Impact actually occurring from cost risk at the specified project time & $\mathrm{ACI}$ \\
\hline 10 & Actual Schedule Impact & $\begin{array}{l}\text { Schedule Impact actually occurring from schedule risk } \\
\text { at the specified project time }\end{array}$ & ASI \\
\hline 11 & Cost Impact Variance & Variance between FCI and ACI calculating at the specified project time & CIV \\
\hline 12 & Schedule Impact Variance & Variance between FSI and ASI calculating at the specified project time & SIV \\
\hline 13 & Actual Response Cost & $\begin{array}{l}\text { Cumulative sum of actual costs responding to the forecasted cost risk } \\
\text { at the specified project time }\end{array}$ & $\mathrm{ARC}$ \\
\hline 14 & Actual Response Days & $\begin{array}{l}\text { Cumulative sum of actual days responding to the forecasted schedule risk at the specified } \\
\text { project time }\end{array}$ & ARD \\
\hline 15 & Cost Risk Response Variance & Variance between ACI and ARC calculating at the specified project time & CRRV \\
\hline 16 & Schedule Risk Response Variance & Variance between ASI and ARD calculating at the specified project time & SRRV \\
\hline 17 & Cost Risk Response Effective & $\begin{array}{l}\text { Actual cost risk response efficiency calculated from dividing CIV by ARC } \\
\text { at the specified project time }\end{array}$ & CRRE \\
\hline 18 & Schedule Risk Response Effective & $\begin{array}{l}\text { Actual schedule risk response efficiency calculated from dividing SIV by ARD } \\
\text { at the specified project time }\end{array}$ & SRRE \\
\hline
\end{tabular}


The risk performance index (RPI) is a performance indicator for measuring the performance of three-dimensional mixed-use space development projects in a view point of risk management, and composed by the similar measurement system as the EVMS. Therefore, the RPI is defined as a performance measurement index that can measure the project performance in view of three different dimensions, cost/schedule/risk, to be upgraded from two dimensions of the EVMS.

\subsection{COMPONENT OF THE RISK PERFORMANCE IN- DEX}

The RPI in this study is not only based on the Schedule Risk Value (SRV) which means a product of schedule risk probability and its impact, and the Cost Risk Value (CRV) which means a product of cost risk probability and its impact of the identified risks inherent in the project, but also the Forecasted Risk Value (FRV) which means a product of forecasted risk probability and its impact, and the Residual Risk Value (RRV) which means a remaining risk value of SRV and CRV. The RPI consists of total 18 detailed indexes, and terminology, definition and abbreviation of these indexes are summarized in Table 2.

\subsection{MEASUREMENT SYSTEM OF THE RISK PER- FORMANCE INDEX}

(1) Cost Risk Performance Index (CRPI)

As noted in Equation (1), the cost risk performance index (CRPI) can be calculated by dividing the forecasted cost risk variance (FCRV) subtracted by the residual cost risk variance (RCRV) at a specific date by the FCRV.

$$
\mathrm{CRPI}=\frac{\mathrm{FCRV}-\mathrm{RCRV}}{\mathrm{FCRV}}
$$

where,

$$
\begin{aligned}
& \text { CRPI : Cost Risk Performance Index } \\
& \text { FCRV : Forecasted Cost Risk Value } \\
& \text { RCRV : Residual Cost Risk Value }
\end{aligned}
$$

The analysis of CRPI can be performed as follows. First, as the CRPI is " 1 ", it means perfect elimination of the cost risk because the RCRV is " 0 ", in other words, the cost risk shows a best status because the cost risks inherent in the project is " 0 ". Second, as the CRPI is larger than " 0 " and smaller than " 1 ", it shows that the RCRV is lower than the FCRV. It means that although some risks still exist in the project, it shows a low risk level compared to the forecasted risk and can be considered that the cost risk shows a good status. Third, as the CRPI is " 0 ", it shows that the FCRV is equal to the RCRV. It means that the cost risks are no reduction and an unchanged status. Fourth, as the CRPI is less than " 0 ", it shows that the RCRV exceeds the FCRV. It means that the cost risks are increased and a bad status. Table 3 shows the CRPI and its analysis method.
Table 3. CRPI Analysis

\begin{tabular}{c|l}
\hline Index & \multicolumn{1}{c}{ Description } \\
\hline CRPI $=1$ & $\begin{array}{l}\text { Best status, residual cost risk is 0, all cost risks have been } \\
\text { eliminated. }\end{array}$ \\
\hline $0<\mathrm{CRPI}<1$ & $\begin{array}{l}\text { Good status, residual cost risks are smaller than forecasted } \\
\text { cost risks. }\end{array}$ \\
\hline $\mathrm{CRPI}=0$ & $\begin{array}{l}\text { Unchanged status, residual cost risks are equal to forecasted } \\
\text { cost risks. }\end{array}$ \\
\hline $\mathrm{CRPI}<0$ & $\begin{array}{l}\text { Bad status, residual cost risks are larger than forecasted cost } \\
\text { risks. }\end{array}$ \\
\hline
\end{tabular}

(2) Schedule Risk Performance Index (SRPI)

The schedule risk performance index (SRPI) can be calculated by dividing the forecasted schedule risk variance (FSRV) subtracted by the residual schedule risk variance (RSRV) in a specific date by the FSRV. The calculation formula can be expressed as Equation (2).

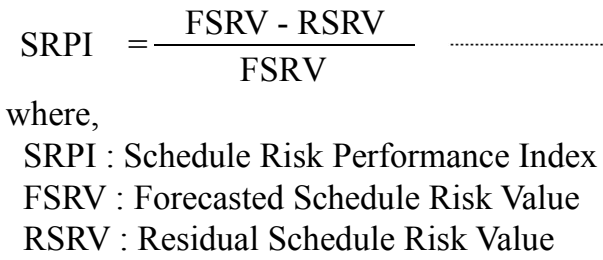

Table 4. SRPI Analysis

\begin{tabular}{c|l}
\hline Index & \multicolumn{1}{|c}{ Description } \\
\hline SRPI $=1$ & $\begin{array}{l}\text { Best status, residual schedule risk is 0, all schedule risks have } \\
\text { been eliminated }\end{array}$ \\
\hline $0<\mathrm{SRPI}<1$ & $\begin{array}{l}\text { Good status, residual schedule risks are smaller than forecasted } \\
\text { schedule risks. }\end{array}$ \\
\hline SRPI $=0$ & $\begin{array}{l}\text { Unchanged status, residual schedule risks are equal to fore- } \\
\text { casted schedule risks }\end{array}$ \\
\hline SRPI $<0$ & $\begin{array}{l}\text { Bad status, residual schedule risks are larger than forecasted } \\
\text { schedule risks. }\end{array}$ \\
\hline
\end{tabular}

The SRPI can be analyzed as follows. First, as the SRPI is " 1 ", it means perfect elimination of the schedule risk because the RSRV is " 0 ", in other words, the schedule risk shows a best status because the schedule risk inherent in the project is " 0 ". Second, as the SRPI is larger than " 0 " and smaller than " 1 ", it shows that the RSRV is lower than the FSRV. It means that although some risks still exist in the project, it shows a low risk level compared to the forecasted risk and can be considered that the schedule risk shows a good status. Third, as the SRPI is " 0 ", it shows that the FSRV is equal to the RSRV. It means that the schedule risks are no reduction and an unchanged status. Fourth, as the SRPI is less than " 0 ", it shows that the RSRV exceeds the FSRV. It means that the schedule risks are increased and a bad status. Table 4 shows the SRPI and its analysis method.

(3) Integrated Cost/Schedule Risk Performance Indexes It is possible to monitor a continuous changing status of 
the cost/schedule risk performance indexes which are integrated by the CRPI and SRPI, using the indication method in a quadrant at particular measurement dates as illustrated in Figure 1.

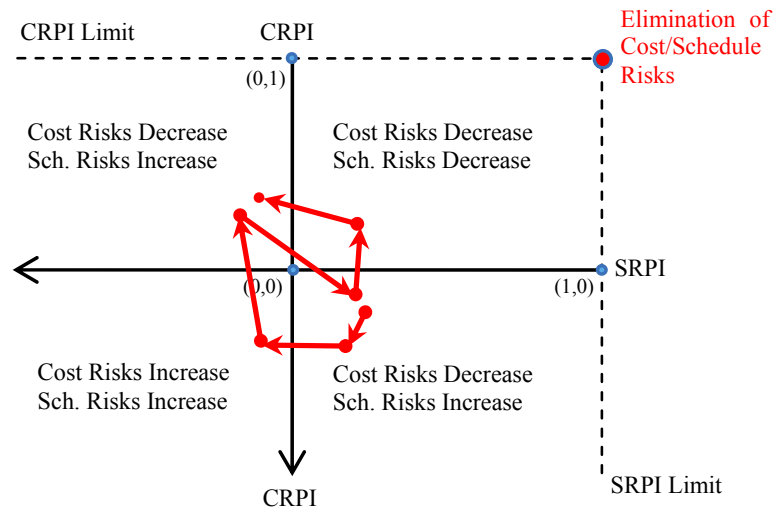

Figure 1. Integrated Cost/Schedule Risk Performance Measurement

The analysis of an integrated chart of the cost/schedule risk performance index can be performed as follows. First, as the CRPI and SRPI are " 1 ", it shows a best status where the cost/schedule risks are totally removed. Second, as the CRPI and SRPI are larger than " 0 ", it shows a good status where the cost and schedule risks are all reduced. Third, as the CRPI is larger than " 0 ", but the SRPI is smaller than "0", the cost risks are decreased, but the schedule risks are increased. It means that the schedule risks should be reduced. Fourth, the CRPI is smaller than " 0 ", but the SRPI is larger than " 0 ", the cost risks are increased, but the schedule risks are decreased. It means that the schedule risks should be reduced. Fifth, as the CRPI and SRPI are smaller than " 0 ", the cost/schedule risks are significantly increased. It means that a project status has been worsen and needs more intensive risk management.

(4) Cost Impact Variance (CIV), Schedule Impact Variance (SIV)

$$
\begin{aligned}
& \text { where, } \\
& \text { CIV : Cost Impact Variance } \\
& \text { FCI : Forecasted Cost Impact } \\
& \text { ACI : Actual Cost Impact } \\
& \text { SIV : Schedule Impact Variance } \\
& \text { CIV }=\text { FCI - ACI } \\
& \text { SIV }=\text { FSI - ASI }
\end{aligned}
$$

FSI : Forecasted Schedule Impact

ASI : Actual Schedule Impact

The cost impact variance (CIV) and the schedule impact variance (SIV) are the performance indexes that can determine whether or not the risk response is effectively executed by comparing differences between the forecasted cost/schedule impact (FCI/FSI) and the actual cost/schedule impact (ACI/ASI) at a particular date. These can be calculated by using Equations (3) and (4), respectively. The analysis of the CIV and SIV can be performed as noted in Table 5.

Table 5. CIV, SIV Analysis

\begin{tabular}{c|l}
\hline Index & \multicolumn{1}{|c}{ Description } \\
\hline CIV $>0$ & $\begin{array}{l}\text { ACI is less than FCI, risk response has been efficient or cost } \\
\text { risk has been decreased. }\end{array}$ \\
\hline CIV $<0$ & $\begin{array}{l}\text { ACI is greater than FCI, risk response has been inefficient or } \\
\text { cost risk has been increased. }\end{array}$ \\
\hline SIV $>0$ & $\begin{array}{l}\text { ASI is less than FSI, risk response has been efficient or sche- } \\
\text { dule risk has been decreased. }\end{array}$ \\
\hline SIV $<0$ & $\begin{array}{l}\text { ASI is greater than FSI, risk response has been inefficient or } \\
\text { schedule risk has been increased. }\end{array}$ \\
\hline
\end{tabular}

(5) Cost Risk Response Variance (CRRV), Schedule Risk Response Variance (SRRV)

The cost risk response variance (CRRV) shows the difference between the actual cost impact (ACI) and the actual response cost (ARC) measured at a particular date, and the schedule risk response variance (SRRV) represents the difference between the actual schedule impact (ASI) and the actual response days (ASD) measured at a particular date. These values can be calculated by using Equations (5) and (6), respectively.

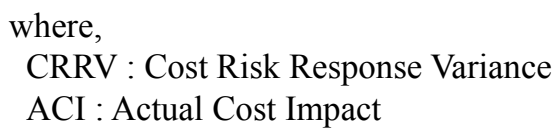

ARC : Actual Response Cost

SRRV : Schedule Risk Response Variance

ASI : Actual Schedule Impact

ARD : Actual Response Days

Table 6. CRRV, SRRV Analysis

\begin{tabular}{c|l}
\hline Index & \multicolumn{1}{c}{ Description } \\
\hline CRRV $>0$ & Cost risk response strategies are good. \\
\hline CRRV $<0$ & Cost risk response strategies are bad \\
\hline SRRV $>0$ & Schedule risk response strategies are good \\
\hline SRRV $<0$ & Schedule risk response strategies are bad \\
\hline
\end{tabular}

The analysis of the CRRV and SRRV can be performed as noted in Table 6.

(6) Integrated Cost/Schedule Risk Response Variances

It is possible to monitor a continuous changing status of the cost/schedule risk response strategy's efficiency by integrating the CRRV and SRRV, using the indication method in a quadrant at particular measurement dates as illustrated in Figure 2. 


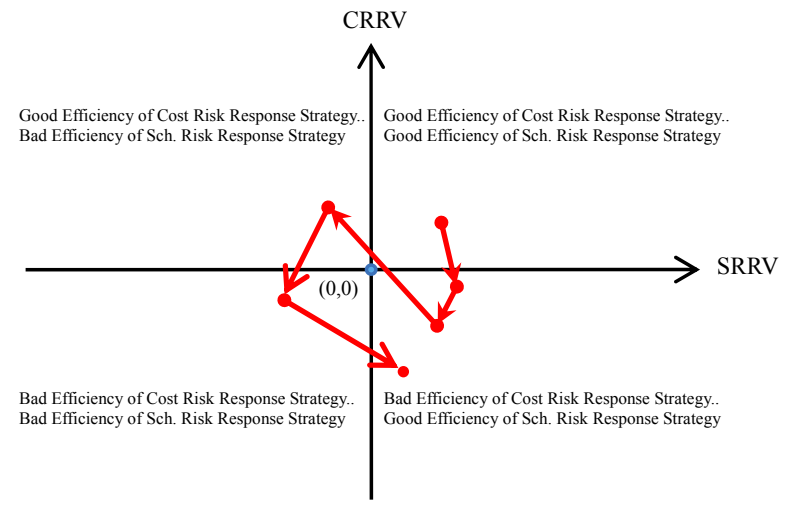

Figure 2. Integrated Cost/Sch. Risk Response Variance Measurement

The analysis of an integrated chart of the cost/schedule risk response variances can be performed as follows. First, as the CRRV and SRRV are larger than "0", it shows the efficiency of the response strategies is a good status, and it means that the response strategies have been successfully implemented. Second, as the CRRV is larger than " 0 " but the SRRV is smaller than " 0 ", the cost risk response strategy efficiency is a good status but schedule risk response strategy efficiency is a bad status. It means that the schedule response strategy should be planned more carefully and implemented more efficiently. Third, as the CRRV is smaller than " 0 " but the SRRV is larger than " 0 ", the cost risk response strategy efficiency is a bad status but schedule risk response strategy efficiency is a good status. It means that the cost response strategy should be planned more carefully and implemented more efficiently. Fourth, as the CRRV and SRRV are smaller than "0", the efficiency of the cost/schedule risk response strategy represents a bad status. It means that both of the cost/schedule response strategy should be planned more carefully and implemented more efficiently.

\section{(7) Cost Risk Response Efficiency (CRRE)}

The cost risk response efficiency (CRRE) is an index that measures an efficiency of the actual cost impact (ACI) vs. the forecasted cost impact (FCI) at a particular date. However, the change curves of FCI, ACI, and actual response cost (ARC) during a whole project life show different tendencies respectively. Generally, the changes in three curves are started from " 0 ", and reach to a peak point at $3 / 4$ of the development phase, and finally become " 0 " at a project completion. The scale of changes in curves can assume that FCI is the largest and then in the order of ACI and ARC, but these order may be changed according to the project and risk characteristics. Figure 3 illustrates the tendency in the change of FCI, ACI, and ARC.

The difference between FCI and ACI becomes the CIV, and the difference between ACI and ARC becomes the CRRV.

As shown in Figure 3, the CRRE at a particular date during a whole project life can be obtained by dividing the
CIV by the ARC. Then, it can be expressed as Equation (7).

$$
\mathrm{CRRE}=\frac{\mathrm{CIV}}{\mathrm{ARC}}
$$

where,

$$
\begin{aligned}
& \text { CRRE : Cost Risk Response Effective } \\
& \text { CIV : Cost Impact Variance } \\
& \text { ARC : Actual Response Cost }
\end{aligned}
$$

The analysis of the CRRE can be performed as follows. First, as the CRRE is larger than " 1 ", it shows a good status in the CRRE because the ARC is larger than the CIV. It means that the cost risk response efficiency is high. Second, as the CRRE is "1", there is no CRRE because the $\mathrm{CIV}$ is equal to the ARC. It means that the cost risk response has no efficiency. Third, as the CRRE is smaller than "1", the CRRE shows a bad status because the CIV at a particular point is larger than the ARC. It means that the cost risk response efficiency is low. The analysis method of the CRRE is summarized in Table 7.

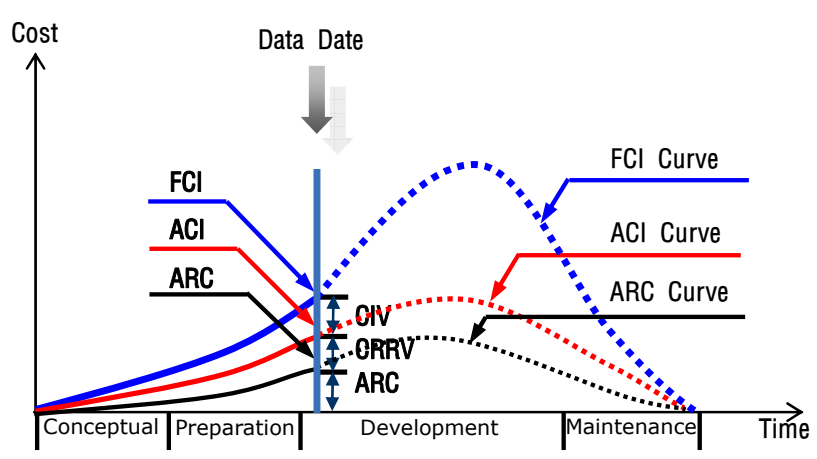

Figure 3. Relationship between Forecasted/Actual Cost Impact and Actual Response Cost

Table 7. CRRE Analysis

\begin{tabular}{c|l}
\hline Index & \multicolumn{1}{c}{ Description } \\
\hline CRRE $>1$ & Cost Risk Response Efficiency is good. \\
\hline CRRE $=1$ & Cost Risk Response has no Efficiency \\
\hline CRRE $<1$ & Cost Risk Response Efficiency is bad \\
\hline
\end{tabular}

(8) Schedule Risk Response Efficiency (SRRE)

The schedule risk response efficiency (SRRE) is an index that measures an efficiency of the actual schedule impact (ASI) vs. the forecasted schedule impact (FSI) at a particular date.

The difference between the FSI and the ASI becomes the SIV, and the difference between the ASI and the ARD becomes the SRRV.

The SRRE at a particular date during the period of the project can be obtained by dividing the SIV by the ARD. Then, it can be expressed as Equation (8).

$$
\mathrm{SRRE}=\frac{\mathrm{SIV}}{\mathrm{ARD}} \quad \cdots
$$




\section{Qualitative Risk Performance Measurement Table}

\begin{tabular}{|c|c|c|c|c|c|c|c|c|c|c|c|c|c|c|c|c|c|c|c|c|c|c|c|c|c|c|c|c|c|c|c|c|c|}
\hline \multirow{4}{*}{$\begin{array}{l}\text { Risk } \\
\text { ID }\end{array}$} & \multirow{4}{*}{ Description } & \multirow{4}{*}{ Weight } & \multicolumn{15}{|c|}{ Previous Forecast Date : 2008. 10. 1} & \multicolumn{14}{|c|}{ Base Date : 2009. 1. 1} & & \\
\hline & & & \multicolumn{15}{|c|}{ Forecasted RV } & \multicolumn{14}{|c|}{ Residual RV } & \multicolumn{2}{|c|}{ RPI } \\
\hline & & & \multicolumn{4}{|c|}{$\begin{array}{l}\text { Probability } \\
\text { Scale }\end{array}$} & \multicolumn{4}{|c|}{$\begin{array}{l}\text { Cost Impact } \\
\text { Scale }\end{array}$} & \multirow[t]{2}{*}{ FCRV } & \multicolumn{5}{|c|}{$\begin{array}{c}\text { Schedule Impact } \\
\text { Scale }\end{array}$} & \multirow[t]{2}{*}{ FSRV } & \multicolumn{4}{|c|}{$\begin{array}{l}\text { Probability } \\
\text { Scale }\end{array}$} & \multicolumn{4}{|c|}{$\begin{array}{l}\text { Cost Impact } \\
\text { Scale }\end{array}$} & \multirow[t]{2}{*}{ RCRV } & \multicolumn{4}{|c|}{$\begin{array}{c}\text { Schedule Impact } \\
\text { Scale }\end{array}$} & \multirow[t]{2}{*}{ RSRV } & \multirow[t]{2}{*}{ CRPI } & \multirow[t]{2}{*}{ SRPI } \\
\hline & & & 1 & $\begin{array}{lll}2 & 3 \\
\end{array}$ & 4 & 5 & 1 & 3 & 4 & 5 & & 1 & 2 & 3 & 4 & 5 & & \begin{tabular}{l|l}
1 & 2 \\
\end{tabular} & 3 & 4 & 5 & 12 & 3 & 4 & 5 & & 1 & 2 & 3 & 4 & & & \\
\hline II 3B2003 & $\begin{array}{l}\text { Low rate of } \\
\text { apartment } \\
\text { sales }\end{array}$ & 0.35 & & & $\circ$ & & & & & $\circ$ & 20 & & $\circ$ & & & & 8 & & $\circ$ & & & ० & & & & 6 & & & & ○ & 12 & 0.7 & -0.5 \\
\hline II 3B2003 & $\begin{array}{l}\text { Unreasonable } \\
\text { requests } \\
\text { from nearby } \\
\text { residents }\end{array}$ & 0.24 & & & & ○ & & o & & & 15 & & & 0 & & & 15 & & & 0 & & & & 0 & & 16 & & & o & & 12 & -0.07 & 0.2 \\
\hline & & & & & & & & & & & & & & & & & & & & & & & & & & & & & & & & & \\
\hline
\end{tabular}

Figure 4. Qualitative Risk Performance Measurement Table

where,

SRRE : Schedule Risk Response Effective

SIV : Schedule Impact Variance

ARD : Actual Response Days

The analysis of the SRRE can be performed as follows. First, as the SRRE is larger than " 1 ", it shows a good status in the SRRE because the ARD is larger than the SIV. Second, as the SRRE is "1", there is no SRRE due to the fact that the SIV is the same as the ARD. It means that the schedule risk response has no efficiency Third, as the SRRE is smaller than " 1 ", the SRRE shows a bad status because the SIV at a particular point is larger than the ARD. The analysis of the SRRE can be noted in Table 8 .

Table 8. SRRE Analysis

\begin{tabular}{c|l}
\hline Index & \multicolumn{1}{|c}{ Description } \\
\hline SRRE $>1$ & Schedule Risk Response Efficiency is good. \\
\hline SRRE $=1$ & Schedule Risk Response has no Efficiency \\
\hline SRRE $<1$ & Schedule Risk Response Efficiency is bad \\
\hline
\end{tabular}

\subsection{RISK PERFORMANCE MEASUREMENT TABLE}

It is necessary to produce a table format that can conveniently determine the potential risk factors and impacts in a mega-project through overall analysis of the risk performance indexes and their calculated results. For this purpose, this study proposes two kinds of the table formats. First is a Qualitative Risk Performance Measurement Table which shows the measurement results as qualitative indexes. Second is a Quantitative Risk Performance

Measurement Table which shows the measurement results as quantitative amounts. A Qualitative Risk Performance Measurement Table and a Quantitative Risk Performance Measurement Table are illustrated in Figure 4 and Figure 5, respectively.

A Qualitative Risk Performance Measurement Table shows the Forecasted Risk Value (FRV) composed of the columns for the FCRV and the FSRV that have probability scales, cost and schedule impact scales evaluated at previous forecast date, and the Residual Risk Value (RRV) composed of the columns for the residual cost risk value (RCRV) and the residual schedule risk value (RSRV) that have probability scales, cost and schedule impact scales

\section{Quantitative Risk Performance Measurement Table}

\begin{tabular}{|c|c|c|c|c|c|c|c|c|c|c|c|c|c|c|}
\hline & & & & & (Uni & Thousa & d Won, D & & & $\begin{array}{l}\text { Forec } \\
8.10\end{array}$ & & & $\begin{array}{l}\text { 3ase Dat } \\
009.1 .\end{array}$ & \\
\hline Risk & Deccrintion & Weight & & Cost Ris & Impact// & sponse $E$ & fective & & & hedul & sk Im & Respor & Effective & \\
\hline ID & & & $\mathrm{FCl}$ & $\mathrm{ACl}$ & CIV & ARC & CRRV & CRRE & FSI & ASI & SIV & ARD & SRRV & SRRE \\
\hline II 3B2003 & $\begin{array}{l}\text { Low rate of } \\
\text { apartment } \\
\text { sales }\end{array}$ & 0.35 & 200,000 & 150,000 & 50,000 & 30,000 & 120,000 & 1.67 & 65 & 34 & 29 & 40 & -6 & 0.725 \\
\hline II 3B2003 & $\begin{array}{l}\text { Unreasonable } \\
\text { requests } \\
\text { from nearby } \\
\text { residents }\end{array}$ & 0.24 & 50,000 & 30,000 & 20,000 & 35,000 & $-5,000$ & 0.57 & 35 & 30 & 5 & 4 & 26 & 1.25 \\
\hline & & & & & & & & & & & & & & \\
\hline
\end{tabular}

Figure 5. Quantitative Risk Performance Measurement Table 
evaluated at base date, and the calculated results of the cost risk performance index (CRPI) and the schedule risk performance index (SRPI) at the right-end two columns.

A Quantitative Risk Performance Measurement Table shows the Cost Risk Impact and Response Effective composed of the columns for the forecasted cost impact (FCI), the actual cost impact (ACI), the cost impact variance (CIV), the actual residual cost (ARC), the cost risk response variance (CRRV), and the cost risk response effective (CRRE) evaluated at previous forecast and base dates, and the Schedule Risk Impact and Response Effective composed of the columns for the forecasted schedule impact (FSI), the actual schedule impact (ASI), the schedule impact variance (SIV), the actual residual days (ARD), the schedule risk response variance (SRRV), and the schedule risk response effective (SRRE) evaluated at previous forecast and base dates, respectively.

\section{CONCLUSION}

Recently, the researches on the urban regeneration projects have been increased and performed so extensively. It is a part of the effort that solves some social and economical problems occurred by the deteriorated buildings and degraded infrastructures through new urban regeneration projects or redevelopment projects. However, the urban regeneration projects have the characteristics that can not guarantee a project performance success because the projects have various and complex stakeholders related to these projects and are exposed to lots of risks due to its huge scale. This study proposed a risk performance index method to improve an efficiency of the overall performance measurement for a mega-project by extending a traditional cost/schedule based performance measurement system to an integrated cost/schedule/risk measurement system. The expected effects of a risk performance index method proposed in this study can be summarized as follows:

First, it has a similar system as the EVMS which is a traditional cost/schedule performance measurement system and familiar with project managers.

Second, it is possible to execute the three dimensional performance measurement integrated by cost/schedule/risk through 18 detailed indexes for the risk performance measurement.

Third, it is possible to execute a qualitative risk performance measurement through the cost risk performance index (CRPI) and schedule risk performance index (SRPI).

Fourth, it is possible to execute a quantitative risk performance measurement through the cost impact variance (CIV), the schedule impact variance (SIV), the cost risk response variance (CRRV), and the schedule risk response variance (SRRV).

Fifth, it is possible to establish the concepts of a cost risk response efficiency (CRRE) and schedule risk response efficiency (SRRE) for measuring an efficiency of the actual cost and schedule impact vs. the forecasted cost and schedule impact (FSI) at a particular date..
Furthermore, it is necessary to make continuous efforts for upgrading a risk performance index and measurement system proposed in this study, because the performance measurement of a mega-project becomes more and more important factor of project success.

\section{REFERENCES}

CII (2004) "Benchmarking \& Metrics Implementation Toolkit." Construction Industry Institute, 2004

Department of Energy, "Earned Value Management System", U.S. Department of Energy

Fleming, Q. W. and Koppleman, J. M. (1996) "Earned Value Project Management", Project Management Institute, 1996

Flyvbjerg, B., Bruzelius, N. and Rothengatter, W. (2003), "Megaprojects and Risk-An Anatomy of Ambition", Cambridge University Press, 2003

Kang, M. J. Kim, J. H. and Ha, J. M. (2008) "Development of Indicators Evaluating the Level of Blight in Commercial Zones for Urban Regeneration." Journal of the Architectural Institute of Korea, 2008.2, 227-235

Kaplan, R. S. and Norton, D. P. (1993) "Putting the Balanced Scorecard to Work", Harvard Business Review, 1993

The KPI Working Group (2000) "KPI Report for the Minister for Construction", Department of the Environment, Transportation and the Regions, UK, 2000

(Date of Submission : 2009.7.29) 